Revista Eletrônica de Direito Processual - REDP.

Rio de Janeiro. Ano 10. Volume 17. Número 2. Julho a Dezembro de 2016

Periódico Semestral da Pós-Graduação Stricto Sensu em Direito Processual da UERJ

Patrono: José Carlos Barbosa Moreira. ISSN 1982-7636. pp. 420-438

www.redp.uerj.br

A(S) (DUAS) VERDADE(S) (?) DA INCIDÊNCIA E DO PROCESSO ${ }^{1}$

THE (TWO) TRUTH (TRUTHS) (?) OF INCIDENCE AND THE PROCESS

Lucas Lopes Dória Ferreira

Mestrando em Direito pela Universidade Federal de Alagoas (UFAL). Especialista em Direito Tributário e Processo Tributário pelo Instituto Brasileiro de Estudos Tributário (IBET). Professor convidado da Escola Superior da Magistratura de Alagoas (ESMAL). Ex-Professor de Direito Processual Civil do Centro de Estudo Superior de Maceió (CESMAC). ExAssessor Jurídico de Juiz Federal de $2^{\circ}$ Grau, com lotação no Tribunal Regional Federal da $5^{\text {a }}$ Região. Juiz de Direito.

lldoria@hotmail.com

RESUMO: O presente texto estuda a relação da incidência, na perspectiva do Fato Jurídico em Pontes de Miranda, com a verdade e os reflexos disso sobre processo. Investiga, assim, se a linguagem, manifestada sobretudo pelas provas (Teoria das Provas), seria instrumento capaz de criar a verdade ou teria apenas o condão de revelá-la, meramente.

PALAVRAS-CHAVE: Processo; Prova; Incidência; Fato jurídico; Verdade

ABSTRACT: This paper studies the relationship of the incidence, in view of the Legal Fact Pontes de Miranda, with the truth and reflections on this process. Investigates, so if the language, manifested especially by the evidence (Theory of Evidence), would be an instrument capable of creating the truth or would have the power to reveal it, merely.

KEYWORDS: Process; Evidence; Incidence; Legal fact; Truth.

\title{
Introdução
}

O presente estudo volta seus esforços para investigar, ainda que superficialmente e sem qualquer pretensão de exaustão ou de apresentação de resposta em definitivo, se a Teoria

\footnotetext{
${ }^{1}$ Artigo recebido em 04/01/2016 e aprovado em 01/10/2016.
} 
Revista Eletrônica de Direito Processual - REDP.

Rio de Janeiro. Ano 10. Volume 17. Número 2. Julho a Dezembro de 2016

Periódico Semestral da Pós-Graduação Stricto Sensu em Direito Processual da UERJ

Patrono: José Carlos Barbosa Moreira. ISSN 1982-7636. pp. 420-438

www.redp.uerj.br

do Fato Jurídico, como construída por Pontes de Miranda², seria capaz de servir de método para o encontro da "verdade".

Há de se questionar, destarte, no processo de reflexão, se existe uma "verdade" diferente daquela que possa ser expressa pela linguagem, de modo a problematizar sobre haver duas "verdades": (a) uma inalcançável e (b) outra construída; ou somente uma única, seja a que se confunda com a realidade passada no mundo fenomênico ou apenas a que possa está contida no processo linguístico de materialização.

Assim, é de se responder, no fim de contas, se o processo judicial seria um foro de "construção" ou meramente de "revelação" daquele importante valor jurídico e social: a "verdade".

\section{Regra Jurídica}

A compreensão inicial do fenômeno jurídico passa, necessariamente, pelo conhecimento prévio de alguns conceitos e definições particulares da doutrina que se pretende abordar, dentre o quais se apresenta como central o de "incidência", cuja expressão veio a ser cunhada por Pontes de Miranda (presente mesmo em obra jurídica sua mais antiga e menos difundida, a exemplo do Sistema de Ciência Positiva do Direito ${ }^{3}$ ). Porém, nessa proposta de exposição, será possível observar que um conceito relaciona-se com outro, e este outro com um terceiro. De logo, há de se ver que precede à precisa delimitação da incidência o bom trânsito sobre o que Pontes entendia por "regra jurídica" e quais as características essenciais de constituição do "suporte fático".

O tratamento do conceito de "regra jurídica" na doutrina ponteana, por justiça à sua significativa obra, não prescinde da contextualização com o seu tempo, promovendo o transporte temporal da leitura com todas as cautelas que requer a perenização do pensamento pelo texto. Assim, há de se compreender os porquês de o tratamento conferido à "regra jurídica" não ter contado, no conjunto de duas de suas importantes obras, o Tratado de Direito

\footnotetext{
${ }^{2}$ Destaque-se que a designação "Teoria do Fato Jurídico" não é criação que se atribui a Pontes de Miranda. O contato com sua obra evidencia não tivesse o autor essa espécie de preocupação, voltada a denominar a sua compreensão lógica do Direito. O título, que empresta denominação à construção teórica formulada por Pontes de Miranda, se deve a Marcos Bernardes de Mello, que fez leitura detalhada da obra do autor e difundiu o seu pensamento (MELLO, Marcos Bernardes de. Teoria do Fato Jurídico (Plano da Existência). 12 ed. São Paulo: Saraiva, 2003, p. 3 a 19).

3 "As regras jurídicas incidem no espaço e no tempo a que elas se destinam. Uma vez que se compõe todo o suporte fático, a regra jurídica como que colore o que se compôs." (MIRANDA, Pontes. Sistema de Ciência Positiva do Direito. v. 2. Campinas: Bookseller, 2005, p. 99).
} 
Revista Eletrônica de Direito Processual - REDP.

Rio de Janeiro. Ano 10. Volume 17. Número 2. Julho a Dezembro de 2016

Periódico Semestral da Pós-Graduação Stricto Sensu em Direito Processual da UERJ

Patrono: José Carlos Barbosa Moreira. ISSN 1982-7636. pp. 420-438

www.redp.uerj.br

Privado e o Sistema de Ciência Positiva do Direito, com separação semelhante a que promovera, por exemplo, Humberto Ávila, em seu livro Teoria dos Princípios. Para Ávila, a "norma jurídica", que pode vir a ser subclassificada enquanto regra ou princípio, é produto da interpretação de "texto", o qual representa apenas o enunciado linguístico resultante do processo legislativo ${ }^{4}$. Desse modo, promove o autor, em processo de particularização, que tem início no plano mais genérico, a separação entre lei, norma e regra (e também dos princípios).

Pontes de Miranda, em algumas passagens do Tratado de Direito Privado, trata indistintamente a "regra jurídica" e a "norma". É o que se vê na abertura do Tomo I, em que afirma que: "A regra jurídica é norma com que o homem, ao querer subordinar os fatos a certa ordem e a certa previsibilidade, procurou distribuir os bens da vida."5 A "regra jurídica" ora é posicionada como produto resultante do processo de legislar, quando assevera que: "Há o fato de legislar, que é edictar a regra jurídica...”6, ora como resultado da interpretação promovida sobre o texto de lei, como se pode ler em: "Para que os fatos sejam jurídicos, é preciso que regras jurídicas - isto é, normas abstratas - incidam sôbre eles..."”.

Diferença sutil, ao que tudo indica, com efeito, é a forma com que Pontes trabalhara em seu Sistema de Ciência Positiva do Direito, em que, ao menos, promove a distinção entre a lei - leia-se: o texto, tal qual em Ávila -, e "regra" ou "norma", tomando essas duas expressões como fruto da interpretação. É por isso que afirma deva incidir a regra (ou a norma jurídica), não a lei:

\footnotetext{
“O aplicar a lei porque está na lei, o resolver o sentido literal, porque assim quis o legislador, corresponde ao fazer porque está no Evangelho, no Talmude, no Korão, no Corpus Iuris, porque o nosso pai fez, e ao ingênuo "porque mamãe disse" das criancinhas." 8

"Deve o intérprete (jurisconsulto, juiz) procurar, na aplicação da regra, não o conteúdo dos sinais ópticos ou sonoros (ordens verbais), mas, com o auxílio deles, o que se neles contém, mas ou menos o que se perdeu ou se argumentou no trabalho de expressão. Em vez de início em si, apenas é a lei a forma intermédia, durável, mas dúctil, para conservar o dado, ainda que isso o deforme." 9
}

\footnotetext{
${ }^{4}$ ÁVILA, Humberto. Teoria dos Princípios: da Definição à Aplicação dos Princípios Jurídicos. 14 ${ }^{\mathrm{a}}$ ed. São Paulo: Malheiros Editores, 2013, 33 et seq.

${ }^{5}$ MIRANDA, Pontes de. Tratado de Direito Privado. Tomo I, $3^{\text {a }}$ ed., Rio de Janeiro, Editor Borsoi, 1970 , p. 3.

${ }^{6}$ Idem ibidem.

${ }^{7}$ MIRANDA, Pontes de. Tratado de Direito Privado. Tomo I, $3^{\text {a }}$ ed., Rio de Janeiro, Editor Borsoi, 1970 , p. 6.

${ }^{8}$ MIRANDA, Pontes. Sistema de Ciência Positiva do Direito. v. 2. Campinas: Bookseller, 2005, p. 102.

${ }^{9}$ MIRANDA, Pontes de. Tratado de Direito Privado, Tomo I, $3^{\mathrm{a}}$ ed., Rio de Janeiro, Editor Borsoi, 1970, p. 103.
} 
Revista Eletrônica de Direito Processual - REDP.

Rio de Janeiro. Ano 10. Volume 17. Número 2. Julho a Dezembro de 2016

Periódico Semestral da Pós-Graduação Stricto Sensu em Direito Processual da UERJ

Patrono: José Carlos Barbosa Moreira. ISSN 1982-7636. pp. 420-438

www.redp.uerj.br

A construção de Humberto Ávila serve ao seu tempo, sobretudo à necessidade de se promover a distinção entre princípios e regras; a de Pontes de Miranda, ao dele, em que a preocupação e estudo sobre os princípios não se faziam tão presente quanto nos dias atuais, designado de pós-positivista ou neoconstitucionalista.

Mas, disso, importa destacar, sobretudo para este trabalho, que, para Pontes de Miranda, em quaisquer daquelas obras, o que incide é o produto da interpretação, dê-se a isso o nome de regra ou norma jurídica. Apenas com isso, já é possível entrever não haver, em sua doutrina, a propagação da ideia de que a incidência decorra de movimento lógico-silogístico entre texto e fato, sem a possibilidade de construção mais além ou aquém por parte do intérprete ${ }^{10}$.

Marcos Bernardes de Mello, acredita-se que porquanto tenha identificado a possível imprecisão, ao menos para os tempos de hoje - até porque Pontes, quando pretendia destacar se tratasse de proposição legal, normalmente fazia referência à expressão "norma abstrata"11 , optou pelo uso da expressão "norma jurídica", revelando fosse este o elemento incidente sobre o suporte fático (categoria de compreensão capital), e não a proposição textual ${ }^{12}$.

Assim, há de se concluir que a regra jurídica, na construção de Pontes de Miranda, significava, muitas vezes, a proposição legislativa ${ }^{13}$, in natura. Porém, a interpretação dos textos legislativos resultava, para ele, em determinado produto, qual, chamasse de regra ou norma jurídica, representava o elemento incidente sobre os fatos ${ }^{14}$.

\section{Suporte Fáctico}

Toda mudança no mundo representa um fato ${ }^{15}$. E o direito, enquanto ciência destinada a promover a ordenação do mundo social ${ }^{16}$, trabalha com eles. Assim é que a proposição

\footnotetext{
10 “A subsunção (...) não é fato que se possa considerar característico na vida da regra jurídica. E a razão é evidente: se há qualquer atenuação ou extensão da lei, não se subsume no preceito legal o caso ocorrido, porém noutro preceito diferente ou mais largo do que o contido no direito escrito. É a norma 'superpositiva'... Diante disto e da lição dos fatos, não se há duvidar de ação criadora (ou pelo menos reveladora) do juiz: ele não subsume apenas, também pronuncia julgamento de valor..." (MIRANDA, Pontes. Sistema de Ciência Positiva do Direito. Vol. 2. Campinas: Bookseller, 2005, p. 221).

${ }^{11}$ MIRANDA, Pontes de. Tratado de Direito Privado, Tomo I, $3^{\mathrm{a}}$ ed., Rio de Janeiro, Editor Borsoi, 1970 , p. 6. 12 MELLO, Marcos Bernardes de. Teoria do Fato Jurídico: Plano da Existência. 12a ed. São Paulo: Saraiva, 2003, p. 20.

${ }^{13}$ Ibidem, p. 3.

${ }^{14}$ MIRANDA, Pontes. Sistema de Ciência Positiva do Direito. Vol. 2. Campinas: Bookseller, 2005, p. 221.

${ }^{15}$ MIRANDA, Pontes de. Tratado de Direito Privado, Tomo I, $3^{\text {a }}$ ed., Rio de Janeiro, Editor Borsoi, 1970 , p. 5.
} 
Revista Eletrônica de Direito Processual - REDP.

Rio de Janeiro. Ano 10. Volume 17. Número 2. Julho a Dezembro de 2016

Periódico Semestral da Pós-Graduação Stricto Sensu em Direito Processual da UERJ

Patrono: José Carlos Barbosa Moreira. ISSN 1982-7636. pp. 420-438

www.redp.uerj.br

legislativa faz a previsão de determinado fato (ou conjunto deles), posto que o pretenda disciplinar, sujeitando-o a particular efeito jurídico ${ }^{17}$.

O suporte fáctico, que é conceito pertencente ao mundo comum ${ }^{18}$, representa, primeiramente no plano da proposição legal, a passagem textual que remonta a algum fato, evento ou conduta que, tida por relevante, poderá vir a se consagrar (= ocorrer), exigindo, por isso, disciplinamento ${ }^{19}$. A morte de outrem por conduta intencional de determinado indivíduo é um fato passível de ocorrer, sendo, ainda, no contexto social, altamente relevante, sobretudo por sua capacidade de inquietação coletiva. Por isso, a lei descreve esse fato e classifica-o como ilícito, sujeitando-o à sanção que descrimine a lei penal vigente.

A essa descrição do fato, presente na composição linguística do texto da lei, adjetivase o suporte fáctico com das seguintes expressões: "hipotético" ou "abstrato" - "suporte fáctico hipotético" ou "suporte fáctico abstrato" -, a representar sua generalidade, desprendida de qualquer situação fática real que se tenha verificado. Seguindo o mesmo raciocínio, qualifica-se de "concreto" - "suporte fáctico concreto" - o suporte fáctico que aluda a fato materializado pela experiência da realidade, sujeito, pois, à percepção sensorial comum. É tudo o quanto tenha ocorrido e que houvera sido descrito em enunciado legal qualquer ${ }^{20}$.

\section{A Incidência e os Mundos de Pontes de Miranda}

A incidência é o processo por que passa o fato para poder tornar-se (= ser qualificado de) jurídico. Segundo a teoria de Pontes de Miranda, os fatos (totais) interessam ou não ao Direito $^{21}$. Os que interessem submetem-se à valoração da comunidade jurídica, sendo, portanto, destacados e inscritos, descritivamente, em normas jurídicas abstratas ou hipotéticas (= enunciado normativo).

${ }^{16}$ MIRANDA, Pontes de. Tratado de Direito Privado, Tomo I, $3^{\mathrm{a}}$ ed., Rio de Janeiro, Editor Borsoi, 1970, p. $8 / 9$.

${ }^{17}$ MELLO, Marcos Bernardes de. Teoria do Fato Jurídico: Plano da Existência. 12a ed. São Paulo: Saraiva, 2003 , p. 38.

${ }^{18}$ MIRANDA, Pontes de. Tratado de Direito Privado, Tomo I, $3^{\mathrm{a}}$ ed., Rio de Janeiro, Editor Borsoi, 1970, p. 21.

${ }^{19}$ MELLO, Marcos Bernardes de. Teoria do Fato Jurídico: Plano da Existência. $12^{\mathrm{a}}$ ed. São Paulo: Saraiva, 2003 , p. 38.

${ }^{20}$ MELLO, Marcos Bernardes de. Teoria do Fato Jurídico: Plano da Existência. 12a ed. São Paulo: Saraiva, 2003 , p. 39.

${ }^{21}$ MIRANDA, Pontes de. Tratado de Direito Privado, Tomo I, $3{ }^{a}$ ed., Rio de Janeiro, Editor Borsoi, 1970, p. 6. 
Revista Eletrônica de Direito Processual - REDP.

Rio de Janeiro. Ano 10. Volume 17. Número 2. Julho a Dezembro de 2016

Periódico Semestral da Pós-Graduação Stricto Sensu em Direito Processual da UERJ

Patrono: José Carlos Barbosa Moreira. ISSN 1982-7636. pp. 420-438

www.redp.uerj.br

Tais fatos, previstos abstratamente em proposições legais (ou normativa, como preferira Marcos Bernardes de Mello ${ }^{22}$ ), uma vez compostos na realidade (concreta) da vida, submetem-se à "incidência" da "norma jurídica" - que representa a "eficácia legal" ou "nomológica", para Pontes ${ }^{23}$, e, para Marcos Mello, "eficácia normativa" -, a qual intenta darlhe organização e previsibilidade. A incidência, destarte, funciona como um jogo de identidade, no qual se verifica entre a construção extraída do texto - o que Ávila chama, genericamente, de norma e Pontes, de regra jurídica - e o fato da vida.

Na teoria de Pontes de Miranda, a incidência é considerada como um processo (ou operação) de caimento ${ }^{24-25}$ sobre os fatos, onde a regra jurídica desce e encontra o fato, "colorindo-os" 26 . A metáfora de que se utiliza relativa ao cobrimento dos fatos por alguma coloração, fazendo referência a uma "máquina de impressão", bem serve para explicar a adjetivação dos fatos, que passam a ser qualificados de jurídicos. Assim como a cor adere ao ser, o adjetivo fá-lo em relação ao substantivo. É daí que constrói a ideia de que a incidência faz o fato (tornar-se) jurídico e, assim, tem-se, portanto, o fenômeno da "juridicização" ("= incidência da regra jurídica sôbre os fatos, tornando-os fatos jurídicos" ${ }^{27}$ ).

Essa operação de juridicização, que particulariza e marca, em processo de distinção, determinados fatos, cria (continuamente) um subconjunto dentro do conjunto (macro) que compreende o mundo (geral) dos fatos, ao qual se conferiu o nome de "mundo jurídico". Estabelece-se, assim, a classificação dicotômica entre mundo dos fatos e mundo jurídico, muito embora este pertença, como parte integrante, àquele, dado que o fato jurídico integra, igualmente, o mundo dos fatos. Outra forma de enxergar, figurativamente, essa construção, é relacionar o elemento jurídico a um vírus (não letal e, quem sabe, benévolo) que, dentre todos os seres humanos, infecta apenas alguns, particularizando-os. Assim é possível classificar e

${ }^{22}$ MELLO, Marcos Bernardes de. Teoria do Fato Jurídico: Plano da Existência. 12 a ed. São Paulo: Saraiva, 2003 , p. 39.

${ }^{23}$ MIRANDA, Pontes de. Tratado de Direito Privado, Tomo I, $3^{\mathrm{a}}$ ed., Rio de Janeiro, Editor Borsoi, 1970, p. 17.

${ }^{24}$ MIRANDA, Pontes de. Tratado de Direito Privado, Tomo I, $3^{a}$ ed., Rio de Janeiro, Editor Borsoi, 1970, p. 10 .

25 "Incidir é bater, golpear (caedere), gravar, cair sobre, de modo que, no mundo do pensamento humano, o fato ou os fatos recebam o carimbo da regra jurídica, e se tornam fatos jurídicos. Com isso o Homem tece o mundo jurídico em que ele vive e ficam traçadas pelas regras jurídicas destinos de pessoas, de tribos, e de nações. Por simples incidência de regra jurídica sobre quota legítima para os filhos, as fazendas de A passam, por sua morte, aos seus filhos. Tem-se como capaz, para qualquer ato da vida, quem atingiu os anos fixados na lei." (MIRANDA, Pontes. Sistema de Ciência Positiva do Direito. Vol. 2. Campinas: Bookseller, 2005, p. 287).

${ }^{26}$ MIRANDA, Pontes de. Tratado de Direito Privado, Tomo I, $3^{\mathrm{a}}$ ed., Rio de Janeiro, Editor Borsoi, 1970, p. 6.

${ }^{27}$ MIRANDA, Pontes de. Tratado de Direito Privado, Tomo I, $3^{\text {a }}$ ed., Rio de Janeiro, Editor Borsoi, 1970, p. 17. 
Revista Eletrônica de Direito Processual - REDP.

Rio de Janeiro. Ano 10. Volume 17. Número 2. Julho a Dezembro de 2016

Periódico Semestral da Pós-Graduação Stricto Sensu em Direito Processual da UERJ

Patrono: José Carlos Barbosa Moreira. ISSN 1982-7636. pp. 420-438

www.redp.uerj.br

identificar os que são portadores dos que não o são, embora todos continuem a conviver conjunta e caoticamente, sem qualquer espécie de organização segregatória. Semelhantemente aos humanos infectados na figuração construída, os fatos (qualificados de) jurídicos estão dispersos difusamente no mundo geral dos fatos comuns, identificando-se, apenas, pela marca jurídica que carregam consigo (e que, inclusive, pode ser curada pelo processo inverso de desjuridicização ${ }^{28}$ ).

\subsection{A Verdade da Incidência}

A conclusão de que qualquer proposição venha a ser verdadeira ou falsa depende, necessariamente, de um referencial. Isso é verdadeiro em relação a quê? Aquilo é falso tendo em conta o quê? Joana é filha de José e Maria. Essa proposição pode ser considerada verdadeira ou falsa segundo o quê? A prova constrói a paternidade ou a filiação simplesmente é, na essência biológica de sua composição? A linguagem encontra (e coincide com) a verdade ou a cria?

A definição de que determinada asserção seja verdadeira ou falsa passa por um sistema de comparação entre a proposição e o fato real da vida, ao que Adrualdo de Lima Catão, em seu Teoria do Fato Jurídico, designou de "isomorfia” (entre a proposição e o mundo $)^{29}$. Por evidente, não se há negar que tal verificação dependa de um instrumento e sujeite-se - como no ordinário das coisas - a limitações de diversas ordens, podendo, até mesmo, ser a "verdade", concretamente, inalcançável. O instrumento é a linguagem, genericamente falando. Assim é que, dado o seu alcance limitado, determinado fato pode carecer de linguagem - por exemplo: a morte desconhecida ${ }^{30}$-, sem que se possa afirmar não tenha ocorrido. Há de se dizer não haver relato da morte ou mesmo seja apenas provável o passamento, jamais que não ocorrera, mercê da ausência de linguagem. Isso, com efeito, conduz à conclusão de que, diante de interesses outros, não possa uma "nova" verdade vir a

\footnotetext{
${ }^{28}$ MIRANDA, Pontes de. Tratado de Direito Privado, Tomo I, $3^{\text {a }}$ ed., Rio de Janeiro, Editor Borsoi, 1970, p. 114.

${ }^{29}$ CATÃO, Adrualdo de Lima. Teoria do Fato Jurídico: uma Abordagem Lógica da Decisão Judicial. Curitiba: Juruá, 2013, p. 42.

${ }^{30}$ Não se ignora componha a morte desconhecida suporte fáctico concreto do fato jurídico designado de ausência e não o da morte, juridicamente falando, eis que o suporte fáctico deste último fato jurídico é complexo, exigindo, a mais, o conhecimento. Contudo, no corpo do texto, está-se falando, ainda, no plano da linguagem comum, e não da leitura que desta faz o Direito.
} 
Revista Eletrônica de Direito Processual - REDP.

Rio de Janeiro. Ano 10. Volume 17. Número 2. Julho a Dezembro de 2016

Periódico Semestral da Pós-Graduação Stricto Sensu em Direito Processual da UERJ

Patrono: José Carlos Barbosa Moreira. ISSN 1982-7636. pp. 420-438

www.redp.uerj.br

ser "construída" pela linguagem. É, pode-se ver, a linguagem, e, portanto, a prova (como linguagem que é), instrumento destinado a "desvendar" a verdade, não voltado a "criá-la".

A relação entre verdade e incidência passa por problema que bem explora Adrualdo de Lima Catão: a definição do momento em que a incidência normativa ocorre. A incidência seria dependente da constatação da ocorrência do suporte fático concreto pelo sujeito cognoscente ou representaria um fato objetivo, o qual independeria da constatação humana ${ }^{31}$ ?

Pontes de Miranda dirá que "A incidência da lei, pois que passa no mundo dos pensamentos e nêle tem de ser atendida, opera-se no lugar, tempo e outros 'pontos' do mundo, em que tenha de ocorrer, segundo as regras jurídicas. É, portanto, infalível."32 Não há "infalibilidade" humana. Tal característica haveria de passar, portanto, inexoravelmente, no plano imaterial dos pensamentos; transcendente, portanto. A não ser assim, fosse falível, haveria de coincidir com o "atendimento" - a semelhança do que defende corrente relativista (ou realistas, como quer Adriano Soares da $\operatorname{Costa}^{33}$ ). Aqui, alguns problemas descortinar-seiam: (i) dependeria do conhecimento humano; (ii) exigiria conduta humana (o que poderia requisitar processo judicial); e (iii) ter-se-ia duas classificações para único fato revestido de juridicidade.

Parece claro que a incidência é uma metáfora construída na Teoria do Fato Jurídico em Pontes de Miranda para explicar e conferir lógica ao fenômeno jurídico. Não se há de querer compreendê-la no plano concreto, eis que a não é possível ver, sentir ou apanhar a incidência, diferentemente do atendimento, mas tão somente os efeitos que dela decorrem.

Nesse sentido, é bem de ver passagem do Tratado de Direito Privado:

\footnotetext{
"Tudo isso se desenrola mediante o pensamento, que está na regra jurídica (pensar vem de pesar), e incide nos fatos, ainda em queda (incidere, cadere) que só se passa no mundo dos nossos pensamentos, porém que nós vemos em suas consequências: a entrada dos herdeiros na casa, a retirada dos objetos, o alojamento deles, a venda em leilão e a distribuição, entre eles da quantia apurada..." 34
}

\footnotetext{
31 CATÃO, Adrualdo de Lima. Teoria do Fato Jurídico: uma Abordagem Lógica da Decisão Judicial. Curitiba: Juruá, 2013, p. 59.

${ }^{32}$ MIRANDA, Pontes de. Tratado de Direito Privado, Tomo I, $3^{\text {a }}$ ed., Rio de Janeiro: Editor Borsoi, 1970 , p. 16.

${ }^{33}$ COSTA, Adriano Soares. Teoria da Incidência da Norma Jurídica: Crítica ao Realismo Linguístico de Paulo de Barros Carvalho. $2^{a}$ ed., São Paulo: Malheiros, 2009, p. 55.

${ }^{34}$ MIRANDA, Pontes de. Tratado de Direito Privado, Tomo I, $3^{\text {a }}$ ed., Rio de Janeiro, Editor Borsoi, 1970, p. 7.
} 
Revista Eletrônica de Direito Processual - REDP.

Rio de Janeiro. Ano 10. Volume 17. Número 2. Julho a Dezembro de 2016

Periódico Semestral da Pós-Graduação Stricto Sensu em Direito Processual da UERJ

Patrono: José Carlos Barbosa Moreira. ISSN 1982-7636. pp. 420-438

www.redp.uerj.br

Assim é que a incidência qualifica-se como construção teórica segundo a qual se intenta confunda-se com a verdade, pois que representaria a exata correspondência entre os fatos previstos na norma e aqueles ocorridos no mundo fenomênico ${ }^{35}$. É algo como que, consagrado o fato da vida, presente no mundo dos fatos, a norma jurídica, onipresentemente, identificaria o que se passara e sobre tal fato incidiria - "colorindo-o"; adjetivando-o; juridicizando-o -, onde quer que ocorra (também essa característica espacial desfavorece a coincidência pretendida entre incidência e aplicação, dada a limitação da condição humana necessária ao atendimento da regra jurídica). Somente essa construção idealizada da incidência é capaz de explicar como se compreende determinado direito cujos efeitos remetam ao passado, embora seu conhecimento tenha-se dado futuramente. É o que se pode passar, por exemplo, com a regra do artigo 1.784 do Código Civil, quando a morte somente venha a ser conhecida tempos depois. Esse atraso cognitivo do fato da vida (ou, para uns, do evento morte) não prejudica a transmissão da propriedade, que, por conta da incidência, dá-se, infalivelmente, ao tempo do passamento, não importando quão largo tenha sido o período transcorrido.

Observe-se como a teoria pode ter reflexo prático e serve ao propósito de bem aplicar a norma jurídica corretamente. Imagine a situação em que, ao tempo do fato (ou evento, como queira), desconhecido, morte, o de cujos "Y" apenas possuísse um único descendente vivo, designado, para efeito didático, de "A". Considere-se que este, por sua vez, fosse casado, com "B", e sua esposa tivesse apenas um filho unilateral, o "C", o qual não tivesse sido gerado a partir de "A". Além desse possível legítimo sucessor, figure-se que "Y" tivesse, ainda, naquele (fatídico) tempo, vivo seu genitor, "D", qual matinha relação matrimonial com "E", outrem que não o gerara ("Y") e nem consigo matinha qualquer relação parental, vindo, com ela, a conceber "F". Diversamente desse momento, sugere-se se imagine uma conjuntura familiar diferente tempos depois, especificamente quando do conhecimento do fato pesaroso passado, momento em que já tenha igualmente falecido o descendente único (“A”). A se considerar a Teoria do Fato Jurídico ou as teorias relativistas (mais extremadas), ter-se-á resultados absolutamente diferentes. Porém, a teoria que unifique no tempo incidência e aplicação, haverá de, no fim de contas, desprezar o comando de norma cogente, a do artigo 1.784 do Código Civil. É que, ao se considerar a incidência no momento do conhecimento do

\footnotetext{
${ }^{35}$ CATÃO, Adrualdo de Lima. Teoria do Fato Jurídico: uma Abordagem Lógica da Decisão Judicial.
} Curitiba: Juruá, 2013, p. 59. 
Revista Eletrônica de Direito Processual - REDP.

Rio de Janeiro. Ano 10. Volume 17. Número 2. Julho a Dezembro de 2016

Periódico Semestral da Pós-Graduação Stricto Sensu em Direito Processual da UERJ

Patrono: José Carlos Barbosa Moreira. ISSN 1982-7636. pp. 420-438

www.redp.uerj.br

fato (jurídico), haveria de se reconhecer que a herança passaria, consoante regramento do artigo 1.829, inc. II, do Código Civil, ao ascendente em detrimento da cônjuge do descente, a quem caberia a herança, em detrimento daquele, segundo o inciso I daquele mesmo artigo, acaso se considere que a incidência tenha ocorrido, objetiva e infalivelmente, no momento exato da morte, ainda quando viesse a ser conhecida apenas em tempos depois.

Quer parecer, com efeito, que apenas a concepção de que o direito incide e cristalizase no tempo, mesmo que seus efeitos somente venham a ser sentidos tempos depois, ou jamais venham, é capaz de explicar, satisfatoriamente, a necessidade de se regulamentar situações do passado, sem que, nesse tempo, tenham sido captadas por qualquer elemento de linguagem. É por isso que a incidência na Teoria do Fato Jurídico de Pontes de Miranda ocorre tão $\operatorname{logo}$ se verifique o suporte fáctico concreto de determinada norma jurídica, independente de qualquer relato em linguagem ou conhecimento humano ${ }^{36}$; objetivamente, portanto. Daí que essa característica de infalibilidade somente se pode confundir com a verdade, tanto da (i) ocorrência do fato jurídico, como do (ii) conteúdo da norma ${ }^{37}$.

Não por outro motivo que a norma, ao incidir, tão logo capte se tenha concretizado o suporte fáctico, prescindindo, a tanto, de qualquer conduta humana, nem muito menos de relato em alguma espécie de linguagem [que se designe "competente" (?)], identifica a realidade dos fatos passados no plano dos eventos comuns (ou sociais), confundindo-se, destarte, com a verdade. $\mathrm{O}$ que seria a verdade senão aquilo que efetivamente ocorreu? A reconstrução é algo, contudo, que interessa ao plano seguinte: o da aplicação, e não ao da incidência, que se faz verbo passado na instantaneidade da completude do suporte fáctico. A incidência, pois, "cai" sobre o fato, tal qual o raio sobre determinado corpo. Se, porém, esse fato (jurídico) veio a ser do conhecimento de alguém ou se a norma jurídica foi extraída

\footnotetext{
${ }^{36}$ Aqui, discorda-se, com todo o respeito, de Marcos Bernardes de Mello, em passagem que diz o seguinte: "Somente fato cuja ocorrência seja da ciência de alguém, apenas, ou que seja passível de prova pode ser considerado concretizado para os fins de incidência das normas jurídicas." (MELLO, Marcos Bernardes de. Teoria do Fato Jurídico: Plano da Existência. 12a ed. São Paulo: Saraiva, 2003, p. 83.). No presente trabalho, diversamente, não se considera o conhecimento como elemento essencial da incidência, senão acidental. Far-se-á necessário à (perfeição da) incidência, contudo - agindo acidentalmente, porquanto particularizado -, quando o tenha sido previsto no suporte fáctico da regra jurídica. A tanto, parece evoluir também o professor alagoano, quando, em nota de rodapé, ajusta o conhecimento como elemento do suporte fáctico da morte, exemplo com o qual trabalhara no corpo do texto e inserido em continuidade ao trecho pinçado.

37 "A incidência da regra jurídica é que torna jurídico os bens da vida. Muitas vêzes, porém, a incógnita é a regra jurídica; outras vezes, o conjunto de fatos, o suporte fáctico, em que a regra jurídica incide. Ali, responde-se às perguntas - ‘¿Há a regra jurídica e qual é?’; aqui, as duas outras ‘¿Quais os elementos que compõem o suporte fático; e qual a natureza de cada um deles?' Tais questões são inconfundíveis com as da irradiação de efeitos dessa impressão da norma jurídica no suporte fático." (MIRANDA, Pontes de. Tratado de Direito Privado, Tomo I, $3^{\text {a }}$ ed., Rio de Janeiro, Editor Borsoi, 1970, p. XVII)
} 
Revista Eletrônica de Direito Processual - REDP.

Rio de Janeiro. Ano 10. Volume 17. Número 2. Julho a Dezembro de 2016

Periódico Semestral da Pós-Graduação Stricto Sensu em Direito Processual da UERJ

Patrono: José Carlos Barbosa Moreira. ISSN 1982-7636. pp. 420-438

www.redp.uerj.br

corretamente pelo interprete, são questões que, no tempo, sobrepõe-se - e pressupõe - à incidência.

\section{Interpretação e Aplicação do Direito}

\subsection{Distinção entre Incidência e Aplicação}

A norma, enquanto "objetivação conceptual", atinge o suporte fáctico por meio da causalidade jurídica ${ }^{38}$ e, pelos múltiplos processos de "aplicação", sejam espontâneos ou impositivos (é dizer: judicializado), ganha a forma de "objetivação social", cumprindo, com isso, o seu papel de pacificação social. A “objetivação conceptual” se passa no mundo dos pensamentos - que não quer representar a psique particularizada de cada indivíduo ${ }^{39}$-, sendo, por isso, representação simbolizada do processo de juridicização. A aplicação da norma jurídica que incidiu, noutro passo (o seguinte), é que vem representar o segundo conceito, o de "objetivação social", que reproduz, na realidade social, concreta, e não mais idealizada, a “objetivação conceptual” provocada pela incidência jurídica ${ }^{40}$.

É de se entrever que a aplicação, como dito, situa-se em fase posterior à da incidência e, ainda, pressupõe a consagração dela. Nisso, está dito qual o momento da aplicação dentro do fenômeno jurídico e identificado um de seus requisitos, que é exatamente a incidência. Porém, para além disso, faz-se necessário responder a outra ordem de questão: qual o objetivo do processo de aplicação (venha a ser espontâneo ou impositivo)? A aplicação serve ao atendimento à incidência ${ }^{41}$ - pressupondo, antes, por óbvio, o conhecimento do fato e a identificação do conteúdo da norma jurídica incidente -: "A regra jurídica incide; e essa incidência é servida, para seu atendimento menos imperfeito possível, pela tutela jurídica, a

\footnotetext{
${ }^{38}$ MIRANDA, Pontes de. Tratado de Direito Privado, Tomo I, $3^{\text {a }}$ ed., Rio de Janeiro, Editor Borsoi, 1970, p. 18 .

39 “...não era Pontes de Miranda um ingênuo ao formular o conceito operacional de incidência, com se imaginasse ele que as normas jurídicas não precisassem ser interpretadas, produzidas em certo sentido, passando por todo um processo complexo até se tonarem um dado para a sociedade, uma norma viva. (...) A norma jurídica - afirmo eu - é a significação socialmente aceita, vivida e aplicada: é socialmente um dado, um estar-aí, uma vivência intencional. Mas esse dado é proposição vertida em linguagem prescritiva, como objeto cultural que é." (COSTA, Adriano Soares. Teoria da Incidência da Norma Jurídica: Crítica ao Realismo Linguístico de Paulo de Barros Carvalho. $2^{a}$ ed., São Paulo: Malheiros, 2009, p. 45/46)

${ }^{40}$ COSTA, Adriano Soares. Teoria da Incidência da Norma Jurídica: Crítica ao Realismo Linguístico de Paulo de Barros Carvalho. $2^{a}$ ed., São Paulo: Malheiros, 2009, p. 55.

41 "O que se aplicou, o que se respeitou, foi o que se teve como regra jurídica incidente." (MIRANDA, Pontes. Sistema de Ciência Positiva do Direito. Vol. 4. Campinas: Bookseller, 2005, p. 385)
} 
Revista Eletrônica de Direito Processual - REDP.

Rio de Janeiro. Ano 10. Volume 17. Número 2. Julho a Dezembro de 2016

Periódico Semestral da Pós-Graduação Stricto Sensu em Direito Processual da UERJ

Patrono: José Carlos Barbosa Moreira. ISSN 1982-7636. pp. 420-438

www.redp.uerj.br

que corresponde a pretensão à tutela jurídica, em suas múltiplas classes de aplicação das regras jurídicas. $" 42$.

Assim é que, na esteira de Adrualdo de Lima Catão, haveria três substanciais aspectos da norma jurídica que importa sejam destacados. O primeiro deles é a própria incidência, passada, infalivelmente, no mundo dos pensamentos - tendo conformidade Lógica, portanto. O segundo aspecto, não obstante a incidência, diz com a "obediência": cumprimento espontâneo da norma jurídica. Por último, como o atendimento (à norma) é, ao contrário da incidência, falível, o terceiro aspecto é reservado ao atendimento impositivo da norma pelo Estado, na medida em que tenha o comando sido descumprido por seu destinatário.

Nessa construção, é possível perceber a distinção havida em relação às teorias que restringem o fenômeno jurídico ao ato de autoridade - e, pois, à linguagem -, cortando cerce do mundo jurídico os fatos que se tenham dado precedentemente: entre particulares, por exemplo, que, espontaneamente, hajam cumprido o espírito da norma jurídica regente (= incidente). É o que se passa, todos os dias, com aqueles que entram numa cafeteria, sentam-se e pedem um café, saboreiam-no e, ao final de tudo, pagam, regularmente, o preço cobrado pelo estabelecimento. Vê-se, aí, surgir e desenvolver-se uma relação jurídica, cujo ordenamento classifica como compra e venda ${ }^{43}$. Com conduta social comum, o homem abre espaço à incidência da norma jurídica, qual preconiza haver direitos e deveres recíprocos inerentes à relação travada: ao contratante, o direito de receber produto e o dever de pagar o preço; ao contratado, o direito de receber o preço e o dever de entrega do produto. Ao praticarem, cada qual, a conduta que lhes toca na relação jurídica firmada, por imposição causal da norma, há, no fim de contas, a aplicação espontânea do direito posto ${ }^{44}$.

Desconsiderar que nisso haja fenômeno jurídico, talvez signifique trancafiá-lo nos tribunais ou em repartições administrativas, fazendo todos perguntarem onde estaria situada a cogência do direito? Na ameaça de processo, apenas; portanto, na repressão? Ou será que não haveria, na imposição ao cumprimento das normas, uma ordem de caráter social, cujo respeito

\footnotetext{
${ }^{42}$ MIRANDA, Pontes de. Tratado de Direito Privado, Tomo I, $3^{\text {a }}$ ed., Rio de Janeiro, Editor Borsoi, 1970, p. 14.

${ }^{43}$ Código Civil: "Art. 481. Pelo contrato de compra e venda, um dos contratantes se obriga a transferir o domínio de certa coisa, e o outro, a pagar-lhe certo preço em dinheiro."

44 "Não é somente o poder judiciário, aplicador da lei, que concretiza o direito; e, se bem analisarmos a realidade, não somente os poderes políticos: é enorme o coeficiente de aplicação devido à atuação da família, do grupo de amigos, do círculo social, a que chamamos (...) à imitação cristalografia, lâmina ou camadas da sociedade." (MIRANDA, Pontes. Sistema de Ciência Positiva do Direito. Vol. 4. Campinas: Bookseller, 2005, p. 138)
} 
Revista Eletrônica de Direito Processual - REDP.

Rio de Janeiro. Ano 10. Volume 17. Número 2. Julho a Dezembro de 2016

Periódico Semestral da Pós-Graduação Stricto Sensu em Direito Processual da UERJ

Patrono: José Carlos Barbosa Moreira. ISSN 1982-7636. pp. 420-438

www.redp.uerj.br

dar-se-ia não somente por temor (a um órgão ou ente), mas sobretudo por atenção à finalidade do direito: a pacificação e a ordem social.

\subsection{Aplicação como Processo Complexo de Revelação da Verdade Jurídica}

O Direito, enquanto processo de adaptação social ${ }^{45-46}$, intenta sejam observados os comportamentos a que as normas jurídicas prescrevem, sendo tanto melhor que isso se consagre espontaneamente ${ }^{47}$ - o que evidenciará, no plano da análise sociológica, um melhor desenvolvimento cultural de determinada comunidade - , prescindindo, pois, da intervenção estatal (aplicação cogente ou impositiva). Para tanto, não é bastante que as normas jurídicas incidam, pois que passam no plano lógico do mundo dos pensamentos. Faz-se necessário promover a conversão daquilo o quanto fora idealizado em realidade jurídica ${ }^{48}$, para o que não se prescinde da aplicação do Direito, o qual pressuporá o devido atendimento aos comandos jurídicos por aqueles que sejam destinatários da norma.

O processo de aplicação do Direito, contudo, não se revela simplificador da complexidade experimentada na interpretação jurídica - crítica que direcionam a Teoria do Fato Jurídico de Pontes de Miranda ${ }^{49}$-, mercê de a incidência apresentar como um de seus principais destaques a nota característica da infalibilidade, como se fosse bastante identificar o texto de lei incidente sobre determinado fato da vida, numa operação mecanicista. É daí que

45 "Mediante essas regras, consegue o homem diminuir, de muito, o arbitrário da vida social, a desordem dos interesses, o tumultuário dos movimentos humanos à cata do que deseja, ou do que lhe satisfaz algum apetite." (MIRANDA, Pontes de. Tratado de Direito Privado, Tomo I, $3^{\mathrm{a}}$ ed., Rio de Janeiro, Editor Borsoi, 1970, p. IX.)

46 "A regra jurídica é norma com que o homem, ao querer subordinar os fatos a certa ordem e a certa previsibilidade, procurou distribuir os bens da vida." (MIRANDA, Pontes de. Tratado de Direito Privado, Tomo I, $3^{\text {a }}$ ed., Rio de Janeiro, Editor Borsoi, 1970, p. 3.)

${ }^{47}$ Há de se registrar que Pontes de Miranda já destacava que os homens mais atendem do que desobedecem às normas jurídicas (MIRANDA, Pontes de. Tratado de Direito Privado, Tomo I, $3^{\text {a }}$ ed., Rio de Janeiro, Editor Borsoi, 1970, p. 11): o que confere sentido ao ordenamento jurídico, que, caso contrário, sugeriria fosse mais adequado um sistema onde as condutas viessem a ser analisadas posteriormente, porém sem qualquer sinalização de comportamento antecedente. A regra jurídica, como propósito de conferir segurança e previsibilidade, far-seia prescindível. Semelhante observação está, também, em Marcos Bernardes de Mello e em Adriano Soares da Costa (MElLO, Marcos Bernardes de. Teoria do Fato Jurídico: Plano da Existência. 12a ed. São Paulo: Saraiva, 2003, p. 13; COSTA, Adriano Soares. Teoria da Incidência da Norma Jurídica: Crítica ao Realismo Linguístico de Paulo de Barros Carvalho. $2^{a}$ ed., São Paulo: Malheiros, 2009, p. 54.)

${ }^{48}$ Preferiu-se qualificar a expressão realidade, particularizando-a de jurídica, para permitir se compreenda que a realização dos desígnios da norma jurídica nem sempre compreende alteração no plano material, sensível, na medida em que o Direito cria a sua própria realidade. É assim, por exemplo, com o divórcio, que, embora o direito venha a ser aplicado devidamente, com a constituição de uma nova situação jurídica, no plano físico nenhuma alteração haverá de ser perceptível aos sentidos.

49 CATÃO, Adrualdo de Lima. Teoria do Fato Jurídico: uma Abordagem Lógica da Decisão Judicial. Curitiba: Juruá, 2013, p. 139. 
Revista Eletrônica de Direito Processual - REDP.

Rio de Janeiro. Ano 10. Volume 17. Número 2. Julho a Dezembro de 2016

Periódico Semestral da Pós-Graduação Stricto Sensu em Direito Processual da UERJ

Patrono: José Carlos Barbosa Moreira. ISSN 1982-7636. pp. 420-438

www.redp.uerj.br

sobressalta (i) a distinção entre a lei e o produto de sua interpretação, distinguindo aquela da regra ou norma jurídica, e, ainda, (ii) entre incidência e aplicação (o que se promoveu precedentemente).

A iniciar-se pela distinção entre lei e norma jurídica, o processo de aplicação já se revela complexo, haja vista seja necessário extrair do texto, observado todo o contexto, a interpretação jurídica adequada ao seu tempo. O contexto e o tempo são importantes, certamente mais que o texto, na medida em que, para PONTES, o Direito é "ciência de fatos e não de textos" - está aí porque ele o define como processo de adaptação social e não como conjunto de normas ${ }^{50}$. O Direito, assim, por conta do processo de interpretação, revela-se vivo, sujeito, portanto, às contingências do momento em que venha a ser aplicado. A lei, enquanto simples texto, sem referência aos fatos, não é capaz de oferecer uma interpretação que servisse para todo o tempo e sociedade. Se fosse assim, a interpretação seria dotada da mesma "fixidez" ${ }^{1}$ do texto, tornando-se difícil a separação entre eles e sujeitando a evolução da aplicação do Direito à alteração legislativa.

Assim é que a interpretação não prescinde do intérprete. E se assim é, haverá sempre algo de subjetivo na intepretação - sem que, com isso, se queria resvalar para o campo do relativismo absoluto do conteúdo do Direito. Esse elemento subjetivo, por si só, já descortina a distinção que há entre incidência e aplicação, onde aquela, por ser produto lógico e ideal, revela-se, diferentemente, sujeita à objetividade. Mas é daí que se possibilita conciliar o que, aparentemente, não se faria possível: a "fixidez" da lei e a mutação propiciada pela interpretação. Cabe ao intérprete, normalmente ao Juiz, avaliar os fatos que se sobrepuseram ao texto e daí extrair qual a interpretação mais consentânea com o contexto do seu tempo, podendo, por isso, concluir, à semelhança da cláusula rebus sic stantibus, seja determinada aplicação de outrora indevida, seja porque perniciosa ou extemporânea, ou outra razão substancial qualquer ${ }^{52}$.

A aplicação, em Pontes de Miranda, diferentemente da incidência, não se revela como um processo de subsunção, pois que se apresenta como uma análise cognitiva de fatos. A norma jurídica, que tem, normalmente no texto, uma de suas importantes fontes - a qual serve de partida e limite, o que se oporia ao relativismo -, não prescinde, ademais, de método

${ }^{50}$ CATÃO, Adrualdo de Lima. Teoria do Fato Jurídico: uma Abordagem Lógica da Decisão Judicial. Curitiba: Juruá, 2013, p. 142.

${ }^{51}$ Expressão de Pontes de Miranda (MIRANDA, Pontes. Sistema de Ciência Positiva do Direito. Vol. 3. Campinas: Bookseller, 2005, p. 29).

${ }^{52}$ MIRANDA, Pontes. Sistema de Ciência Positiva do Direito. Vol. 2. Campinas: Bookseller, 2005, p. 266. 
Revista Eletrônica de Direito Processual - REDP.

Rio de Janeiro. Ano 10. Volume 17. Número 2. Julho a Dezembro de 2016

Periódico Semestral da Pós-Graduação Stricto Sensu em Direito Processual da UERJ

Patrono: José Carlos Barbosa Moreira. ISSN 1982-7636. pp. 420-438

www.redp.uerj.br

científico e da análise da realidade social e do contexto histórico. Em tudo a linguagem estará presente. E nela, diversos espaços de imprecisões estarão contidos, o que se pode comprovar com a mera possibilidade de compreensão diversa de determinada expressão. É assim que a aplicação do direito revela-se complexa. Porém, isso não conduz ao relativismo de que determinado fato da vida - enquanto fato puro do mundo fenomênico - venha ou não a ter ocorrido segundo o que se haja comprovado. A capacidade de reproduzir linguisticamente um fato é matéria pertinente à teoria das provas. Mas diante de determinado fato, que se estabeleça como realizado, a Teoria do Fato Jurídico terá entrada, cabendo identificar, diante daquele fato, qual a norma jurídica incidente, revelando, com isso, a partir da interpretação, o conteúdo extraído da norma e a verdade jurídica perseguida ao longo de todo o processo interpretativo. Claro que, se as provas não conduzem aos fatos tais como se sucederam, revelarão outro fato, dando ensejo ao desvio de leitura sobre a incidência, tendo-se, na hipótese, erro de aplicação. De semelhante modo, ainda que a prova se ocupe de apresentar os fatos devidamente como se consagraram, é possível que o interprete, no meio do caminho interpretativo, cometa algum deslize, quando, novamente, haverá equívoco na aplicação. Em uma e outra hipótese, pode-se dizer que não terá a aplicação identidade com a verdade jurídica, qual pressupõe o encontro da incidência ocorrida, fatalmente.

\section{Teoria das Prova e a Verdade (Jurídica, e não Formal) do Processo}

No final do item precedente, cunhou-se a expressão "verdade jurídica" como sinônimo de encontro, na fase de aplicação, da norma jurídica incidente, o que pressuporia, ao menos, dois momentos distintos, e, em ambos, o acerto na identificação e construção dos objetos de conhecimento. O primeiro deles está no fato da vida a que a norma jurídica incidente fez jurídico, qualificando-o; o segundo, na interpretação da norma jurídica, a partir do texto legal e da aplicação de métodos científicos, além da pesquisa histórica e da leitura sistemática do ordenamento, tudo contextualizado com o tempo de determinada sociedade.

A "verdade jurídica", aqui desenvolvida, não se identifica com a "verdade de fato", muito embora aquela venha a ser continente em relação a esta. A "verdade de fato" é pressuposto do encontro da "verdade jurídica". Mas aquela depende, invariavelmente, da prova para poder ser encontrada, na medida em que o fato é num instante, reclamando sempre seja reconstruído através da linguagem. A linguagem, contudo, pode reconstruir 
Revista Eletrônica de Direito Processual - REDP.

Rio de Janeiro. Ano 10. Volume 17. Número 2. Julho a Dezembro de 2016

Periódico Semestral da Pós-Graduação Stricto Sensu em Direito Processual da UERJ

Patrono: José Carlos Barbosa Moreira. ISSN 1982-7636. pp. 420-438

www.redp.uerj.br

verdadeiramente o fato ou não; reproduzir uma conotação linguística que com ele coincida ou não. A prova, enquanto método de linguagem do processo, destina-se a reproduzir um fato que tenha ocorrido e que seja importante e/ou determinante para o desenlace da causa, o que deve ter a ver com o ideal de justiça.

Destarte, tem-se na prova uma atividade processual destinada a comprovar a veracidade ou falsidade de uma afirmação sobre determinado fato, passado, que se fez, descritivamente, apresentar no processo ${ }^{53}$. Com isso, há de se compreender que a prova voltase a uma realidade que se argui tenha passado no mundo fenomênico, situando-se aí o que se indicou como "verdade de fato". Isso não quer significar que a prova - falsa - sobre determinado fato não possa conduzir a julgamento equivocado, como o que conclua pela absolvição de um culpado, haja vista tenha determinada testemunha sido convincente em relação ao álibi construído pela defesa técnica do acusado. Há algum distanciamento entre a "verdade de fato" e a "prova sobre o fato". Prova e verdade não são a mesma coisa. É possível, inescondivelmente, que o meio de prova seja insuficiente para alcançar, com certeza, a verdade de fato, algo que se passou, por anos, com as ações de investigação de paternidade, em que os mecanismos existentes não apanhavam o fato, consistente na paternidade genética, mas elementos circundantes desse fato jurídico. E após a sobrevinda do exame de DNA, viuse, não raro, a definição processual não coincidir com a verdade de fato, que veio a ser revelada pelo novo método de investigação.

Assim é que não se vai ao encontro dos relativistas - ou realistas, para Adriano Soares da Costa $^{54}$-, para quem o fato, também o jurídico, é linguagem, fora do qual inexiste ${ }^{55}$. Para essa corrente, portanto, fato jurídico somente será o que puder ser provado, pelos meios admitidos no processo. Se assim for, o processo, desde quando construa uma justificação probatória para a decisão a ser prolatada, cria a sua própria realidade, a qual se confunde com a verdade. Essa concepção defende a absoluta separação entre o mundo fenomênico e aquilo o

\footnotetext{
${ }^{53}$ CATÃO, Adrualdo de Lima. Teoria do Fato Jurídico: uma Abordagem Lógica da Decisão Judicial. Curitiba: Juruá, 2013, p. 146.

${ }^{54}$ COSTA, Adriano Soares. Teoria da Incidência da Norma Jurídica: Crítica ao Realismo Linguístico de Paulo de Barros Carvalho. $2^{a}$ ed., São Paulo: Malheiros, 2009, p. 55.

${ }_{55}$ CARVAlHO, Paulo de Barros. Direito Tributário: Fundamentos Jurídicos da Incidência. São Paulo: Saraiva, 2004, p. 101.
} 
Revista Eletrônica de Direito Processual - REDP.

Rio de Janeiro. Ano 10. Volume 17. Número 2. Julho a Dezembro de 2016

Periódico Semestral da Pós-Graduação Stricto Sensu em Direito Processual da UERJ

Patrono: José Carlos Barbosa Moreira. ISSN 1982-7636. pp. 420-438

www.redp.uerj.br

que venha a ser construído pela linguagem, de modo que não haveria ponto de contato entre a verdade $^{56}$ e prova $^{57}$.

Característico dessa teoria são as palavras de Paulo de Barros Carvalho:

\begin{abstract}
"De ver está que o discurso prescritivo do direito posto indica, fato por fato, os instrumentos credenciados para constituí-los, de tal sorte que os acontecimentos do mundo social que não puderem ser relatados com tais ferramentas de linguagem não ingressam nos domínios do jurídico, por mais evidentes que sejam." ${ }^{58}$
\end{abstract}

A distinção promovida entre a incidência e a aplicação do direito tem absoluta influência na construção de crítica às teses relativistas. Para a Teoria do Fato Jurídico, a intersecção de tempo considerada entre a incidência e a aplicação já indica sejam fenômenos que devam ser considerados autonomamente, o que não há de acontecer na visão relativista. Como seria a linguagem quem construiria a incidência, criando, propriamente, o fato sobre o qual haverá de incidir a norma jurídica, e não meramente reproduzindo um fato que se sucedeu no mundo fenomênico, sujeito ao confronto com norma jurídica previamente vigente, sua concretização dar-se-ia no mesmo instante da aplicação, a sugerir, no mínimo, tenham semelhante significação jurídica. É possível, destarte, nessa perspectiva, notar certa sobreposição da prova sobre a Teoria do Fato Jurídico, máxime porque não haveria o fato jurídico fora do mundo da Teoria da Prova.

Não é como se entende, data máxima vênia. Lê-se que, no momento de aplicação do Direito, é o tempo de volver olhar atendo ao passado, pretendendo, com ele, identificar os fatos, a regra jurídica vigente e o contexto social e jurídico daquele tempo de outrora. Tudo, evidentemente, dependerá de algum meio de prova que seja capaz de revelar o que aconteceu. Mas o meio de provar os fatos pretéritos - e isto já denota a designação em si - não se confundem com eles. Porém, por ser meio, não se pode conferir, entre eles, verdade e prova, uma independência absoluta nem tampouco identidade alguma, pois que, no fim de contas, esta, a prova, existe a serviço daquela, a verdade. Milita em prol dessa distinção a limitação imposta aos meios de prova dentro do processo judicial, a indicar que, ainda quando a verdade

\footnotetext{
${ }^{56}$ A verdade aqui está sendo empregada no sentido não relativista, onde representa algo que efetivamente tenha se passado no mundo fenomênico. A não ser assim, verdade e prova somente podem, para os relativistas, significar a mesma coisa, eis que a prova é quem construiria a verdade.

57 CATÃO, Adrualdo de Lima. Teoria do Fato Jurídico: uma Abordagem Lógica da Decisão Judicial. Curitiba: Juruá, 2013, p. 147.

${ }^{58}$ CARVAlHO, Paulo de Barros. Direito Tributário: Fundamentos Jurídicos da Incidência. São Paulo: Saraiva, 2004, p. 102.
} 
Revista Eletrônica de Direito Processual - REDP.

Rio de Janeiro. Ano 10. Volume 17. Número 2. Julho a Dezembro de 2016

Periódico Semestral da Pós-Graduação Stricto Sensu em Direito Processual da UERJ

Patrono: José Carlos Barbosa Moreira. ISSN 1982-7636. pp. 420-438

www.redp.uerj.br

não venha a ser atingida, mesmo assim a demanda haverá de ter um fim, eis que outros valores, que não somente o da verdade, também contam com prestígio no cenário jurídicosocial, a exemplo da segurança jurídica, que encontra, no processo judicial, o seu ponto mais destacado.

Dizer que o processo haverá de chegar a um fim independente de encontrar a verdade - o que se dará segundo as provas que tenham sido produzidas ao longo da instrução processual - não significa defender haja uma verdade processual e outra real. A verdade é única. Pode o processo encontrá-la ou não. Mas, de todo modo, o processo constrói enunciado sobre o qual confere sustentação à sua conclusão. Embora legítimo, não se confunde com a verdade e nem tampouco constrói outra, chamada de processual. Apenas, tendo em conta os demais valores que informam o sistema jurídico, confere, dentro das limitações impostas, uma resposta que possa ser satisfatoriamente aceita e autoritativamente respeitada, restabelecendo, pois, a paz social perseguida.

Assim é que a decisão final do processo, que venha a ser acobertada pelo manto protetor da coisa julgada soberana, resolve, ao menos juridicamente, o litígio, mas não revela necessariamente a verdade e, portanto, igualmente a incidência. Muito embora, após isso, o que se tenha passado com a incidência venha a se traduzir em termos de irrelevante jurídico, bem serve para pontuar que linguagem não constrói o Direito, sob o foro de uma verdade processual diferente da real, mas destina-se a reproduzir fatos e a construir soluções jurídicas, observando, para tanto, todos os valores que informa o sistema, dentre os quais se insere a verdade, mas também o tempo, a segurança jurídica e a paz social ${ }^{59}$.

\section{Conclusão}

O presente estudo chega a bom porto com a conclusão de que a Teoria do Fato Jurídico representa uma inteligente construção lógica para explicar o fenômeno jurídico, com grande serventia pragmática. Dentro da construção, conclui-se que a incidência, enquanto elemento ideal, alcança, infalivelmente, a "verdade do fato" e da "interpretação da norma jurídica", havendo, entre aquele, fato do mundo fenomênico, e o fato provado no processo, significativa distinção conceptual, muito embora a prova se destine a perscrutar

\footnotetext{
${ }^{59}$ CATÃO, Adrualdo de Lima. Teoria do Fato Jurídico: uma Abordagem Lógica da Decisão Judicial.
} Curitiba: Juruá, 2013, p. 160. 
Revista Eletrônica de Direito Processual - REDP.

Rio de Janeiro. Ano 10. Volume 17. Número 2. Julho a Dezembro de 2016

Periódico Semestral da Pós-Graduação Stricto Sensu em Direito Processual da UERJ

Patrono: José Carlos Barbosa Moreira. ISSN 1982-7636. pp. 420-438

www.redp.uerj.br

substancialmente os contornos daquele. E a prova, assim como o processo de interpretação, serve ao desvendar da incidência, porém no processo subsequente de aplicação do direito, do qual se serve o intérprete, que pode, ou não, chegar ao encontro daquela que representa a "verdade jurídica".

A Teoria do Fato Jurídico, destarte, é bem sucedida em explicar o seu objeto de estudo e não se confunde com a Teoria da Prova. Esta teoria atua superveniente àquela, mas é vocacionada a desvendar o que se passou ao longo de todo o fenômeno jurídico submetido a exame, o qual é explicado pela primeira teoria, que tem a segunda como instrumento de revelação.

\section{REFERÊNCIAS BIBLIOGRÁFICAS}

ÁVILA, Humberto. Teoria dos Princípios: da Definição à Aplicação dos Princípios jurídicos. $14^{\mathrm{a}}$ ed. São Paulo: Malheiros Editores, 2013.

CARVALHO, Paulo de Barros. Direito Tributário: Fundamentos Jurídicos da Incidência. São Paulo: Saraiva, 2004.

CATÃO, Adrualdo de Lima. Teoria do Fato Jurídico: uma Abordagem Lógica da Decisão Judicial. Curitiba: Juruá, 2013.

COSTA, Adriano Soares. Teoria da Incidência da Norma Jurídica: Crítica ao Realismo Linguístico de Paulo de Barros Carvalho. $2^{\mathrm{a}}$ ed., São Paulo: Malheiros, 2009.

MELLO, Marcos Bernardes de. Teoria do Fato Jurídico: Plano da Existência. 12a ed. São Paulo: Saraiva, 2003.

MIRANDA, Pontes de. Tratado de Direito Privado. Tomo I, $3^{\text {a }}$ ed., Rio de Janeiro, Editor Borsoi, 1970.

. Sistema de Ciência Positiva do Direito. Vol. 2. Campinas: Bookseller, 2005. Sistema de Ciência Positiva do Direito. Vol. 4. Campinas: Bookseller, 2005. 